\title{
Peptidase Modulation of the Pulmonary Effects of Tachykinins in Tracheal Superfused Guinea Pig Lungs
}

\author{
Milton A. Martins, ${ }^{\star}$ Stephanie A. Shore, ${ }^{\star}$ Norma P. Gerard, ${ }^{\star}$ Craig Gerard, ${ }^{5}$ and Jeffrey M. Drazen**s \\ ${ }^{\S}$ Ina Sue Permultter Laboratory, Children's Hospital, *Departments of Medicine, Beth Israel and Brigham and Women's Hospitals and \\ Harvard Medical School, ${ }^{\ddagger}$ Respiratory Biology Program, Harvard School of Public Health, Boston, Massachusetts 02215
}

\begin{abstract}
The effects of the angiotensin converting enzyme (ACE) inhibitor captopril and the neutral endopeptidase (NEP) inhibitors thiorphan and SCH 32615 on the changes in airway opening pressure (Pao) and the recovery of offered peptide were studied after intratracheal administration of substance $P$ (SP) and neurokinin A (NKA) in isolated guinea pig lungs superfused through the trachea. Pao changes and the recovery of offered peptide were significantly greater in NEP inhibitor-treated lungs than in control lungs. Captopril did not cause a significant change in the physiological effects or the recovery of SP and NKA. HPLC analysis of $\left[{ }^{3} H_{]}\right.$Pro $^{2,4}-S P$ and ${ }^{125}$ I-Histidyl ${ }^{1}-$ NKA perfused through the airways showed major cleavage products consistent with NEP action. We conclude that there is significant degradation of both SP and NKA after tracheal infusion of peptides by NEP-like but not by ACE activity; this effect significantly influences the physiological effects of these peptides. (J. Clin. Invest. 1990. 85:170-176.) EC 3.4.24.11 • neuropeptides • tachykinins
\end{abstract}

\section{Introduction}

Substance P (SP) ${ }^{1}$ and neurokinin A (NKA) are two small structurally related bioactive peptides found in certain sensory nerves in the lung $(1,2)$. These peptides are known to transduce a variety of biological effects in the lung including the stimulation of mucus secretion $(3,4)$, the promotion of active epithelial chloride transport (5), enhanced vascular permeability $(6,7)$, and airway smooth muscle contraction (8-10). Although these peptides are extremely potent biomolecules, their physiological effects in vitro and in vivo appear to be limited by their rapid degradation at or near the site of their release (11-14). SP can be degraded by several peptidases, including neutral endopeptidase (EC 3.4.24.11, NEP) $(15,16)$ and an-

Presented in part at the 1989 Annual Meeting of the American Thoracic Society, Cincinnati, $\mathrm{OH}$.

Address reprint requests to Dr. Drazen, Beth Israel Hospital, 330 Brookline Avenue, Boston, MA 02215.

Received for publication 5 July 1989 and in revised form 8 September 1989.

1. Abbreviations used in this paper: $\mathrm{ACE}$, angiotensin converting enzyme; NEP, neutral endopeptidase; NKA, neurokinin A; Pao, airway opening pressure; SCH 32615, ( $N$-[L-(-1-carboxy-2-phenyl)ethyl]-Lphenylalanyl-B-alanine); SP, substance P; TCBLCB, thiorphan, captopril, bestatin, leupeptin, chymostatin, and bacitracin.

J. Clin. Invest.

(c) The American Society for Clinical Investigation, Inc 0021-9738/90/01/0170/07 \$2.00

Volume 85, January 1990, 170-176 giotensin converting enzyme (EC 3.14.5.1, ACE) $(17,18,19)$. NKA is also known to be a substrate for NEP (20) but not lung ACE (21).

Although these peptides are subject to degradation by NEP and ACE, the relative importance of these degradative mechanisms in limiting airway effects is also regulated by the locus of the catabolizing enzyme relative to the site of peptide administration or release. For example when SP is administered to guinea pigs by the vascular route its activity is controlled by both ACE and NEP $(22,23)$. When SP is administered by aerosol, NEP inhibitors enhance its bronchoconstrictor activity (24); the effects of ACE inhibitors on this response are not known. Since NEP is predominantly an epithelial enzyme, whereas ACE is an endothelial one (25), we reasoned that ACE would not be important in modulating the effects of tachykinins after administration via the airways. In order to test this hypothesis we used the airway superfused lung preparation of Nucci and Moncada (26).

\section{Methods}

Tracheal perfusion. 120 male Hartley strain guinea pigs, $240-430 \mathrm{~g}$ body wt, were anesthetized with sodium pentobarbital $(65 \mathrm{mg} / \mathrm{kg}$ i.p.), tracheostomized, and the abdominal wall was opened to expose the aorta and vena cava. Heparin ( $500 \mathrm{U}$ ) was infused into the vena cava and $3 \mathrm{~min}$ later the abdominal aorta was cut. The thoracic wall was removed and the heart and lungs removed en bloc. The lungs were placed in a plexiglass box, kept at $37^{\circ} \mathrm{C}$ and $100 \%$ relative humidity, and the tracheal cannula was connected to a perfusion system (see below). The lungs were superfused with a phosphate-buffered physiological solution whose composition was $\mathrm{NaCl} 137 \mathrm{mM}, \mathrm{CaCl}_{2} 1.8 \mathrm{mM}$, $\mathrm{MgCl}_{2} 1.05 \mathrm{mM}, \mathrm{KCl} 2.68 \mathrm{mM}, \mathrm{NaHCO}_{3} 0.06 \mathrm{mM}, \mathrm{NaH}_{2} \mathrm{PO}_{4} 0.13$ $\mathrm{mM}$, and $\mathrm{Na}_{2} \mathrm{HPO}_{4} 0.869 \mathrm{mM}, \mathrm{pH}$ 7.4. The perfusion fluid was warmed to $45^{\circ} \mathrm{C}$ outside the plexiglass box to drive excess gas from it, then cooled to $37^{\circ} \mathrm{C}$ and passed through a bubble trap before entering the lungs via the trachea. The perfusion rate was $5 \mathrm{ml} / \mathrm{min}$. The perfusate was allowed to leave the lungs through numerous small holes made in the pleural surface with a 25-gauge needle and collected in plastic tubes containing ice-cold glacial acetic acid such that the final concentration of acetic acid in each fraction was $5 \%$ by volume. There was a side tap at the end of the tracheal cannula that was connected to a pressure transducer (P23Db; Statham Instruments, Inc., Oxnard, CA) for measurement of airway opening pressure (Pao).

Assay of substance $P$ and neurokinin $A$. SP and NKA levels in the perfusate were measured by a solid phase enzyme linked immunosorbent assay (ELISA). The ELISA for SP was performed as described by Folkersson et al. (27) using commercially available antiserum. The lower limit of detection was $\mathbf{3} \mathrm{fmol}$ of SP; we found $<0.01 \%$ cross-reactivity with substance $P$ 1-6, substance $P$ 1-9 or NKA.

The ELISA for NKA was performed with minor modifications of the technique used to measure SP. Specifically the solutions to be assayed were incubated with the antibody at $4^{\circ} \mathrm{C}$ for $44-50 \mathrm{~h}$ and transferred to microtiter plates previously cooled to $4^{\circ} \mathrm{C}$. The plates were incubated for an additional $45 \mathrm{~min}$ at $4^{\circ} \mathrm{C}$ before the addition of the secondary antibody. This assay has a sensitivity of $1 \mathrm{fmol} \mathrm{NKA}$; the 
antibody used has $<3 \%$ cross-reactivity with $\mathrm{SP}$ and $<0.1 \%$ with neurokinin A 1-8.

HPLC separation. As indicated samples for analysis were resuspended in $100 \mu \mathrm{l}$ of water with $0.1 \%$ TFA and chromatographed on a $C_{18}$ reverse-phase HPLC column ( $\mu$ Bondapak, $39 \times 300 \mathrm{~mm}$; Waters Instruments, Milford, MA). The column was eluted with a linear gradient from 0.7 to $56 \%$ acetonitrile with $0.1 \%$ TFA over $25 \mathrm{~min} ; 0.5$ to $1.0 \mathrm{ml}$ fractions were collected and the presence of radiolabel detected by scintillation spectrophotometry. The retention times of the radiolabeled peptides were compared to the retention times for substance $P$ $1-6$, substance P 1-7, substance P 1-9, SP, neurokinin A 1-5, neurokinin A 1-8, and NKA as detected by monitoring the absorbance of the eluate at $220 \mathrm{nM}$. Retention times for dipeptides Arg-Pro and Lys-Pro were determined from Thiele et al. (21).

Sample preparation. The perfusates to be studied were centrifuged for $15 \mathrm{~min}$ at $1,000 \mathrm{~g}$ to remove cells and passed through $\mathrm{C}_{18}$ cartridges (Sep-Pak; Waters Associates). The cartridges were washed with $3 \mathrm{ml}$ of water and eluted with $8 \mathrm{ml}$ of $70 \%$ acetonitrile in water with $0.1 \%$ trifluoroacetic acid (TFA). This procedure resulted in a recovery of $80-85 \%$ of $\left[{ }^{3} \mathrm{H}\right] \mathrm{Prolyl}^{2,4} \mathrm{SP}$ and ${ }^{125} \mathrm{I}-\mathrm{Histidyl}{ }^{1} \mathrm{NKA}$. The eluates were dried under vacuum and kept at $-20^{\circ} \mathrm{C}$ until the assays were performed.

\section{Experimental protocols}

Protocol 1. In the first protocol dose-response curves of SP, NKA, and methacholine were constructed. After the lungs were placed in the perfusion apparatus, a period of 15-20 min was allowed for the lungs to equilibrate. Doses of 1,10 , or $100 \mathrm{pmol}$ of either SP or NKA diluted in $100 \mu \mathrm{l}$ of perfusion buffer were rapidly injected into the tracheal perfusate; only one dose of peptide was given to each lung ( $n=3$ for each dose/peptide). To construct the methacholine dose-response curves three separate lungs were studied. In these studies doses of 0.01 , $0.1,1$, and $10 \mathrm{nmol}$ of methacholine each diluted in $100 \mu \mathrm{l}$ of perfusion buffer were infused into the trachea. Sufficient time was allowed before the first dose to achieve a stable baseline pressure and between successive doses for tracheal perfusion pressure to return near to baseline conditions. We also studied the effects of tracheal infusion of doses of 1,10 , and $100 \mathrm{nmol}$ of NKA 1-8 and SP 1-9 (three lungs for each peptide).

Protocol 2. In the second protocol the effects of various enzyme inhibitors (see below) on airway pressure and peptide recovery after tracheal administration of SP and NKA was examined. 10-15 min after the lungs were placed in the perfusion system the buffer was changed to contain either: (a) no enzyme inhibitors (control); (b) captopril $3 \mu \mathrm{M}$; (c) thiorphan $1 \mu \mathrm{M}$; (d) SCH $3261510 \mu \mathrm{M} ;(e)$ a combination of thiorphan $1 \mu \mathrm{M}$, captopril $3 \mu \mathrm{M}$, bestatin $1 \mu \mathrm{M}$, leupeptin 4 $\mu \mathrm{g} / \mathrm{ml}$, chymostatin $4 \mu \mathrm{g} / \mathrm{ml}$, and bacitracin $100 \mu \mathrm{g} / \mathrm{ml}$ (TCBLCB). After 10-15 min more of perfusion under one of these five conditions, $10 \mathrm{pmol}$ of either SP or NKA in $100 \mu l$ of perfusion buffer was administered as in protocol 1. The perfusate was collected for $15 \mathrm{~min}$ to measure SP and NKA recovery. Five lungs were studied under each condition. To establish recoveries in the absence of peptide metabolism on two occasions $10 \mathrm{pmol}$ of either SP and NKA was passed through the perfusion system alone. The peptides were collected and processed as described above; this value was taken as $100 \%$ recovery.

Protocol 3. In the third protocol the metabolism of $\left.{ }^{3} \mathrm{H}\right] \mathrm{Prolyl} 1^{2,4} \mathrm{SP}$ and ${ }^{125}$ I-Histidyl ${ }^{1} \mathrm{NKA}$ was studied. $1.2 \times 10^{6} \mathrm{cpm}$ of ${ }^{3} \mathrm{H}-\mathrm{SP}$ or $2 \times 10^{5}$ cpm of ${ }^{125}$ I-NKA together with $10 \mathrm{pmol}$ of the corresponding nonlabeled peptide was infused into the trachea under the same five experimental conditions described in protocol 2 above; three lungs were studied under each condition. The perfusate was collected after the infusion of peptide in five fractions corresponding to periods of $0-1$, $1-2.5,2.5-5,5-10$, and 10-15 min after injection of SP or NKA.

Materials. SP, SP fragments (1-6, 1-7, and 1-9), SP antisera and NKA antisera were acquired from Peninsula Laboratories, Belmont, CA. Bacitracin, leupeptin, chymostatin, bestatin, and methacholine chloride were purchased from Sigma Chemical, St. Louis, MO. $\left[{ }^{3} \mathrm{H}\right]-$ Prolyl $^{2,4}$ SP and ${ }^{125}$ I-Histidyl ${ }^{1}$ NKA were acquired from Amersham
Corp., Arlington Heights, IL. Captopril was the kind gift of Squibb Pharmaceuticals, Princeton, NJ; SCH 32615 was the kind gift of Schering Pharmaceuticals, Kenilworth, NJ. Neurokinin A 1-5, neurokinin A 1-8, and NKA were prepared by custom synthesis (Multiple Peptide Systems, San Diego, CA).

Statistical analysis. All values are expressed as means \pm SE. The differences between two means were studied using Student's $t$ test. The statistical significance of differences among more than two means was determined by analysis of variance (ANOVA). $P<0.05$ was considered significant. To determine which groups were different when the analysis of variance indicated a significant difference, the NewmanKeuls test was used.

\section{Results}

Fig. 1 shows the time course of Pao changes after tracheal administration of 10 pmol of either NKA or SP without the addition of any enzyme inhibitors. The peak pressure was reached $\sim 1 \mathrm{~min}$ after the infusion of the agonist and decayed thereafter; the total duration of physiological effect was 10-15 min. Peak pressure changes were significantly $(P<0.01)$ higher after NKA than after SP administration. Fig. 2 shows the relationships between peak Pao changes and dose of the agonist infused via the trachea, for SP, NKA, and methacholine. Both SP and NKA were potent contractile agonists being more effective than methacholine in this model. SP $1-9$ or NKA 1-8 had no effect on Pao (data not shown).

The effects of the various enzyme inhibitors on the pressure response to SP and NKA are shown, respectively in Figs. 3 and 4. Treatment with thiorphan, SCH 32615, or TCBLCB enhanced Pao changes, whereas treatment with captopril did not. There were significant differences in the mean pressure changes between SP control group and the groups treated with thiorphan, SCH 32615, and TCBLCB $(P<0.001)$. Similarly, there were significant differences between the effects observed in the NKA control group and the three groups treated with NEP inhibitors $(P<0.001)$. Captopril treatment did not cause any significant increase in the airway effects of SP or NKA compared to control values. The addition of other peptidase inhibitors to thiorphan did not result in any additional contractile effect for either NKA or SP. Mean pressure changes in the SCH 32615 group were significantly higher than in thiorphan and TCBLCB groups $(P<0.001)$ in both the NKA and the SP experiments. To rule out the presence of a nonspecific effect of SCH 32615 on the airways, we studied the effects of this compound on methacholine infusion via the trachea (20 $\mu \mathrm{g}$ in $100 \mu \mathrm{l}$ perfusion buffer) in tracheal superfused lungs. There was no significant difference in Pao changes between the control $\left(13.62 \pm 0.56 \mathrm{~cm} \mathrm{H}_{2} \mathrm{O}\right.$, mean of $\left.10 \mathrm{~min}\right)$ and the group

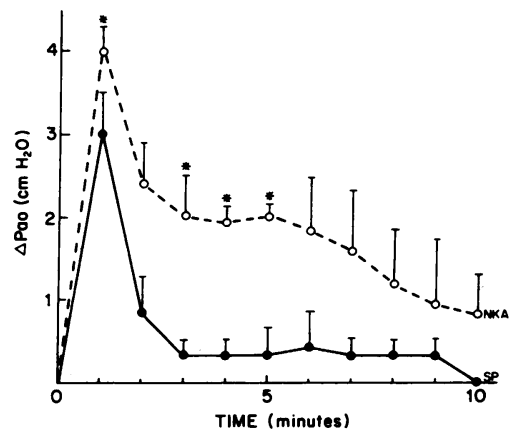

Figure 1. Effects of SP and NKA $(10$ pmol $)$ administered via the trachea at time 0 on airway opening pressure (Pao). Each value is the mean $\pm \mathrm{SE}$ of three lungs. - - SP; - - -, NKA. *Significantly higher than SP $(P<0.05)$ 


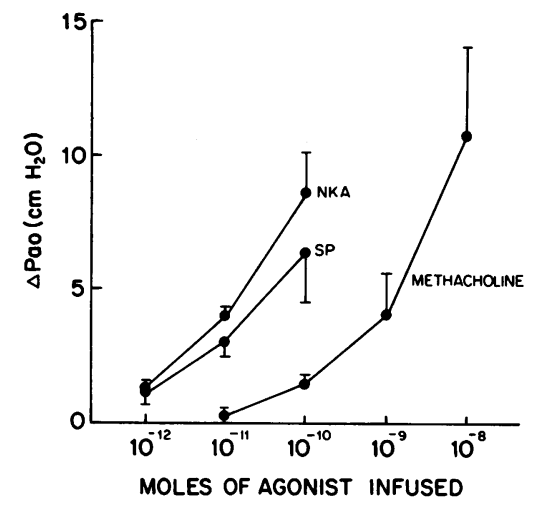

perfused with a buffer with SCH $3261510 \mu \mathrm{M}(15.48 \pm 1.59 \mathrm{~cm}$ $\mathrm{H}_{2} \mathrm{O}$ ) ( $n=5$ for each group of lungs).

The recovery of peptides in the perfusate collected for 15 min after tracheal infusion of SP or NKA as determined by ELISA is shown in Figs. 3 and 4, respectively. Both thiorphan and SCH 32615 led to a significant increase in SP and NKA recovery $(P<0.025$ and $P<0.001$ for $\mathrm{SP}$ and $P<0.05$ and $P$ $<0.025$ for NKA, respectively). The addition of other peptidase inhibitors to thiorphan, i.e., TCBLCB, did not result in recovery values significantly higher than thiorphan alone when either SP or NKA was the offered peptide. Captopril pretreatment did not result in a significant increase in SP or NKA recovery values compared with lungs not treated with enzyme inhibitors.

Similar relative recoveries of SP and NKA were obtained when the radiolabeled moieties were used to monitor peptide recovery. $89.7 \pm 0.76 \%$ and $90.9 \pm 0.99 \%$ of the recovered label, respectively, for SP and NKA were present in the perfusate corresponding to the first $5 \mathrm{~min}$ of perfusion after the infusion of peptide. Of this, $63.80 \pm 1.62 \%$ and $55.55 \pm 0.56 \%$ were recovered as the intact peptide, for SP and NKA, respectively. Fig. 5 illustrates the recoveries of intact peptide over the first 5 min after infusion for both SP and NKA alone and in the presence of the various enzyme antagonists, expressed as percent of total label infused. There was a significant increase in the amount of peptide recovered in the presence of thiorphan, SCH 32615, and TCBLCB for both SP and NKA compared with the absence of enzyme inhibitors $(P<0.005$ for both SP

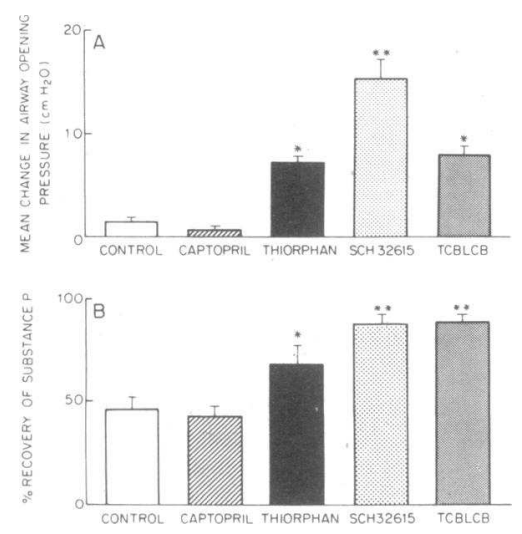

Figure 3. (A) Pao changes after tracheal infusion of $10 \mathrm{pmol}$ of substance $\mathbf{P}$ (SP). Each value is the mean $\pm \mathrm{SE}$ of five lungs. ${ }^{*} P$ $<0.001$ compared to control and captopril groups; ${ }^{* *} P<0.001$ compared to thiorphan and TCBLCB groups. (B) Immunoreactive SP recovered from lung perfusates, expressed as percent of recovery, after infusion of 10

pmol of SP. Each value is the mean \pm SE of five lungs. ${ }^{*} P<0.025$ and ${ }^{* *} P<0.001$ compared to control and captopril groups.

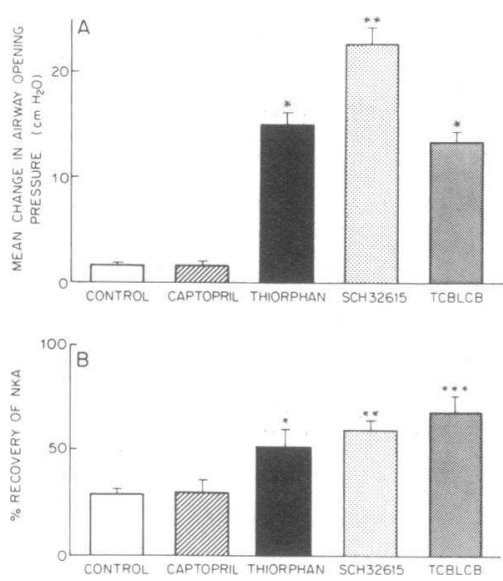

Figure 4. (A) Pao changes after tracheal infusion of $10 \mathrm{pmol}$ of neurokinin A (NKA). Each value is the mean $\pm \mathrm{SE}$ of five lungs. ${ }^{*} P<0.001$ compared to control and captopril groups; ${ }^{* *} P<0.001$ compared with thiorphan and TCBLCB groups. (B) Immunoreactive neurokinin $A$ (NKA) recovered from lung perfusates, expressed as percentage of recovery, after infusion of $10 \mathrm{pmol}$ of NKA.

Each value is the mean $\pm \mathrm{SE}$ of five lungs. ${ }^{*} P<0.05,{ }^{* *} P<0.025$, and ${ }^{* * *} P<0.005$ compared to control and captopril groups.

and NKA). There was no increase in recovered SP or NKA after treatment with captopril. In contrast to the airway effects, where SCH 32615 had an additional effect compared with thiorphan or TCBLCB, there was not an increase in the amount of SP or NKA recovered in the presence of SCH 32615 compared to that recovered in the presence of thiorphan or TCBLCB.

The various degradation products resulting from cleavage of SP or NKA, as estimated by the elution of radiolabeled product from RP-HPLC are shown in Fig. 6 as well as Tables I and II. In the absence of enzyme inhibitors when SP was the offered peptide, the major cleavage products recovered cochromatographed with SP 1-9, SP 1-7, SP 1-6, and the dipeptides Arg-Pro and Lys-Pro. When NKA was offered to lungs in the absence of enzyme antagonists the major products recovered co-chromatographed with methoxy-NKA, NKA 1-8, NKA 1-5, and the dipeptide His-Lys. The perfusates from lungs treated with thiorphan, SCH 32615 , or TCBLCB groups showed an increase in the recovery of SP $1-11$ and a decrease in the formation of SP 1-7 and SP 1-6 relative to the recoveries in the absence of enzyme inhibitors. The amount of radioactivity recovered at the retention times of NKA 1-5 and NKA 1-8 was significantly lower after the treatment with thiorphan, SCH 32615 or TCBLCB compared with control or captopril groups $(P<0.01$ for NKA $1-5$ and $P<0.05$ for NKA $1-8)$.

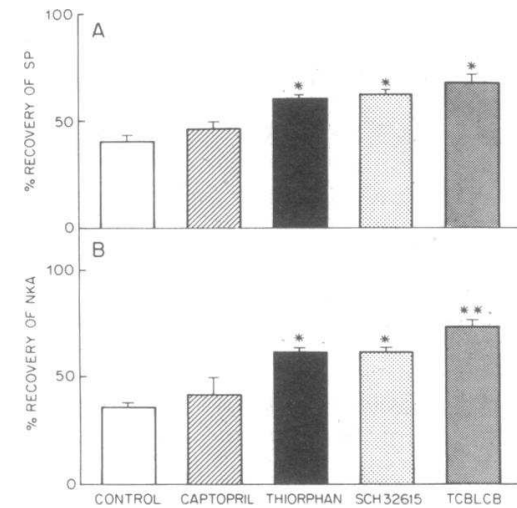

Figure 5. Recovery of intact $\mathrm{SP}(A)$ or NKA $(B)$ over the first $5 \mathrm{~min}$ after tracheal infusion using RP-HPLC. expressed as percent of radiolabel infused. Each value is the mean $\pm \mathrm{SE}$ of three lungs; ${ }^{*} P$ $<0.005 ; * * P<0.001$ compared to control values. 


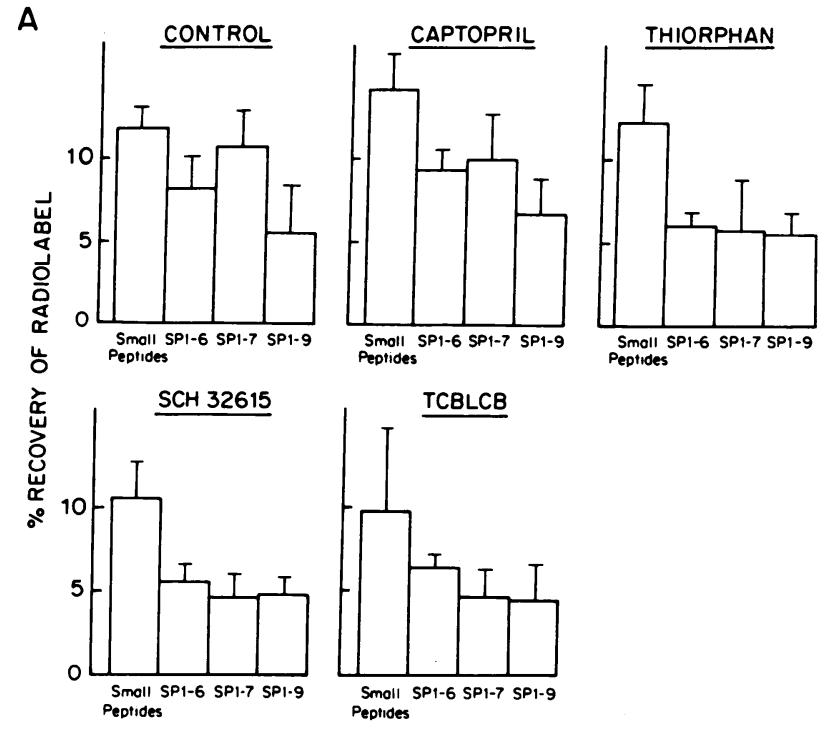

B

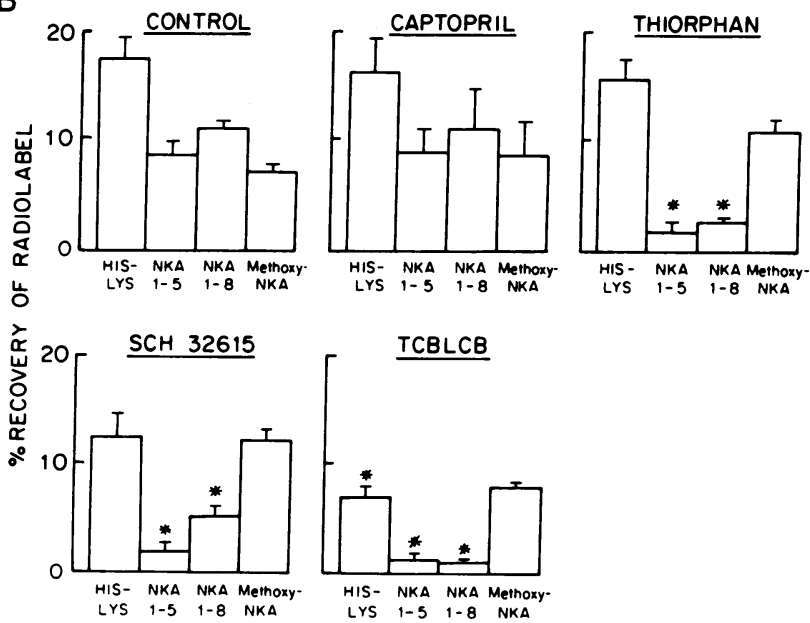

Figure 6. $(A)\left[{ }^{3} \mathrm{H}\right]$ Prolyl ${ }^{2,4}$-substance $\mathrm{P}$ metabolites as identified by retention times of respective standards on reverse-phase high-performance liquid chromatography, expressed as percent of total radiolabel eluted. Values correspond to radiolabel recovered during the first 5 min of lung perfusion. Each value is the mean $\pm S E$ of three lungs. $(B){ }^{125}$ I-Histidyl' ${ }^{1}$ NKA metabolites as identified by retention times of respective standards on reverse-phase HPLC, expressed as percentage of total radiolabel eluted. Values correspond to radiolabel recovered during the first $5 \mathrm{~min}$ of lung perfusion. Each value is the mean $\pm \mathrm{SE}$ of three lungs. ${ }^{*} P<0.05$ compared to control and captopril groups.

TCBLCB treatment also led to a significant decrease in the percentage of label recovered at the retention time of His-Lys ( $P<0.025$ compared to control group). Furthermore, as shown in Tables I and II, the degradation of SP or NKA increased with time; under any given condition the fraction collected over the period from 2.5 to $5 \mathrm{~min}$ after infusion contained more small fragments than did the fraction collected over the first $60 \mathrm{~s}$ after infusion.

\section{Discussion}

We have demonstrated that NEP-like activity but not ACElike activity has a significant influence on SP or NKA induced bronchoconstriction when these tachykinins are presented via the airways. Effects on airway tone and the recovery of peptides were significantly increased when inhibitors of NEP (thiorphan or SCH 32615) were employed, whereas inhibition of ACE with captopril had no significant effect on these parameters.

It is now well established that the enzymatic cleavage of the tachykinins is a major mechanism controlling their physiological effects. In isolated airway tissues treatment with NEP but not ACE inhibitors enhances the responses to SP (12) as well as increases the amount of intact peptide that can be recovered from tissue bath fluids. Similarly when intact guinea pigs are exposed to aerosols of SP the changes in pulmonary resistance are enhanced by NEP inhibitors (24). These data are in contrast to the effects observed when SP is offered to the lungs by the vascular route. In this case both NEP and ACE appear to have major roles limiting the airway effects of $\operatorname{SP}(22,23)$. It seemed likely that the difference between these two observations resulted from the fact that ACE is predominantly an endothelial enzyme while NEP is predominantly an epithelial enzyme. To test this hypothesis we used the tracheal superfused lung preparation described by Nucci and Moncada (26). This preparation allows one to administer agents to the airway but not the pulmonary vascular surface while allowing for quantitation of both effects on airway tone and peptide recovery. In our preparation, the buffer entered the lungs via the trachea and was allowed to leave the lungs through numerous small holes made in the pleural surface. In preliminary studies we ascertained that when about 10 holes were made on the visceral pleural surface spread over the lung surface, formation of additional holes did not further lower tracheal perfusion pressure. This provided reasonable evidence that the Pao measurement reflected the resistance to flow through airways and was not influenced by the number or precise location of the pleural surface holes.

We found that this preparation was very sensitive to mediators that cause an increase in airway smooth muscle tone. This included not only SP and NKA but also methacholine. In isolated contractile tissues it has been shown that guinea pig trachea is about 100 times more sensitive to NKA than to SP, while on parenchymal strips the effects of NKA and SP are similar (9). Since the potency of SP and NKA that we observed in the tracheal perfused lung (Figs. 1 and 2) are similar, our results suggest that these peptides have a more peripheral effect in this model.

We chose the concentrations of the various inhibitors used based on published literature values for effective enzyme inhibition. The concentration of captopril used in our study, $3 \mu \mathrm{M}$, is sufficient to completely block SP degradation by purified $\operatorname{ACE}(16,19) .1 \mu \mathrm{M}$ thiorphan almost completely inhibits NEP in in vitro preparations (15). Although thiorphan is also a weak inhibitor of $\mathrm{ACE}$, it is 30 times less potent as an ACE inhibitor than as a NEP inhibitor (28). SCH 32615 is a novel NEP inhibitor (29) with little or no effect on ACE in concentrations up to $10 \mu \mathrm{M}$. We also examined the effects of a combination of four other peptidase inhibitors: bacitracin, leupeptin, chymostatin, and bestatin. The combination of bacitracin, leupeptin, and chymostatin has been shown to prevent SP degradation in rat brain and guinea pig gastrointestinal smooth muscle preparations (30-32). Bestatin, was also used in the TCBLCB group in a concentration known to inhibit aminopeptidases $(33,34)$.

We postulated that cleavage of SP and NKA by NEP would result in peptides that have minimal contractile activity com- 

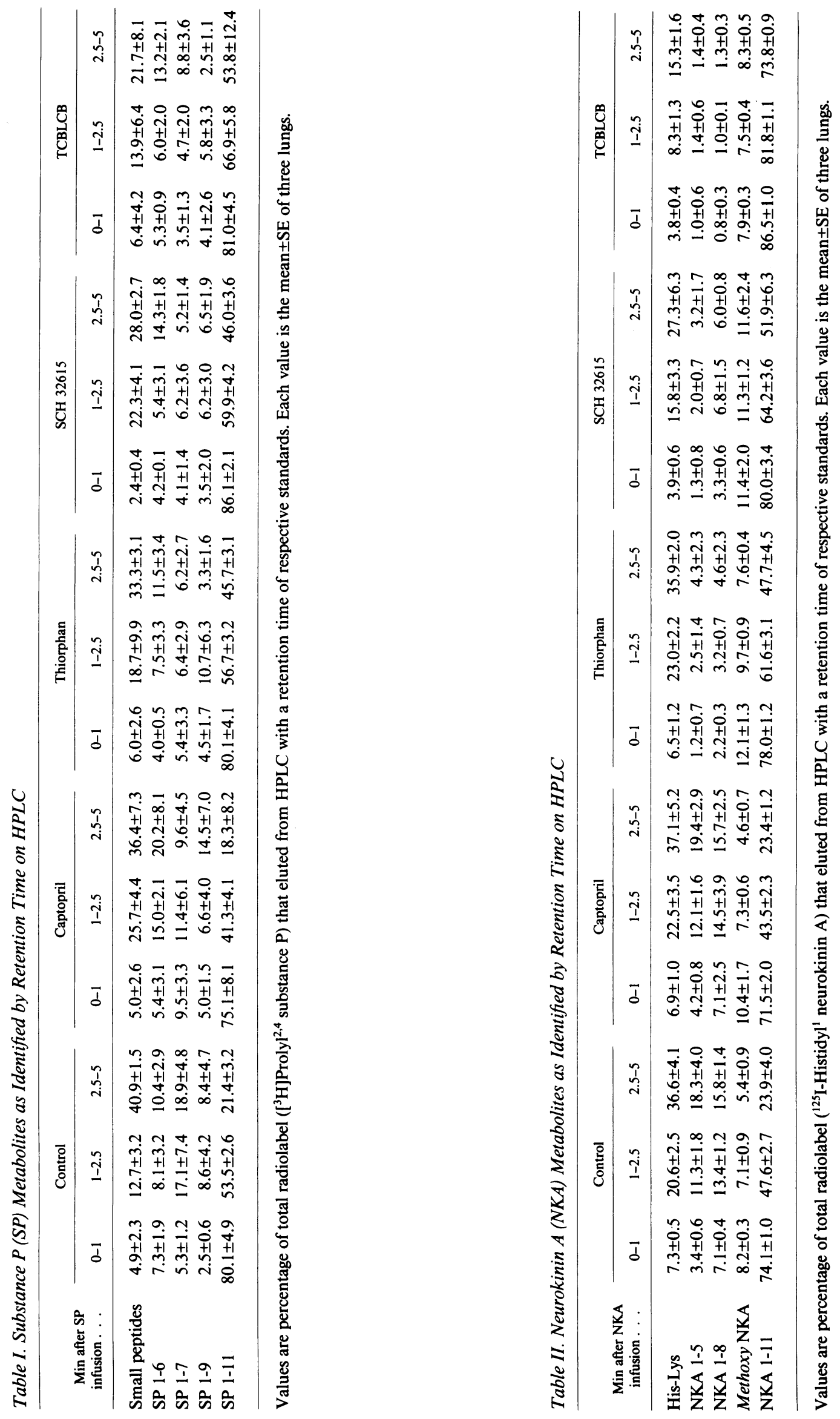

174 M. A. Martins, S. A. Shore, N. P. Gerard, C. Gerard, and J. M. Drazen 
pared with the activity of the native peptides. We studied the effects of SP 1-9 and NKA 1-8, on Pao in our tracheal superfused guinea pig lung preparation. There was no significant airway opening pressure change after administration of these peptides even at doses of $100 \mathrm{nmol}$; thus cleavage of SP and NKA by NEP will inactivate the effects of these peptides on airway contractile elements.

Our data demonstrate that both the effects on airway tone and recovery of offered peptide, be it SP or NKA, are enhanced in the presence of thiorphan or SCH 32615. In contrast there was no significant physiological effect of captopril alone, or any additional effect from TCBLCB compared to thiorphan alone. These data strongly suggest that when these two tachykinins are exposed predominantly to the airway epithelium that NEP is the major enzyme controlling their catabolism. Our data further provide insights into the metabolic fate of these two tachykinins when offered via the airways and thus exposed predominantly to the epithelium. In the absence of enzyme inhibitors both SP and NKA are extensively degraded, over $50 \%$ of offered peptide is degraded to inactive moieties (Figs. 3-5). In the presence of enzyme antagonists the amount of intact peptide recovered increased significantly. This degradation was determined both using an ELISA that recognizes the carboxyl terminus of both peptides and by monitoring the recovery of infused radioactive peptides. The agreement between both methods of estimating recovered peptide provides strong evidence for both peptide breakdown and the inhibition of this breakdown by enzyme antagonists.

The profile of breakdown products obtained after HPLC analysis of lung perfusates obtained after tracheal infusion of $\left[{ }^{3} \mathrm{H}\right] \mathrm{Prolyl}^{2,4} \mathrm{SP}$ and ${ }^{125} \mathrm{I}-\mathrm{Histidyl}{ }^{1} \mathrm{NKA}$ was consistent with a major but not exclusive role for NEP in the metabolism of these peptides. It has been shown that NEP cleaves SP mainly between $\mathrm{Gln}^{6}-\mathrm{Phe}^{7}, \mathrm{Phe}^{7}-\mathrm{Phe}^{8}$, and Gly ${ }^{9}-\mathrm{Leu}^{10}$ generating the (1-6), (1-7), and (1-9) fragments $(16,35)$. Cleavage of NKA by NEP is at the $\mathrm{Ser}^{5}-\mathrm{Phe}^{6}$ and $\mathrm{Gly}^{8}-\mathrm{Leu}^{9}$ positions, resulting in the (1-5) and (1-8) fragments (20). The decrease in the formation of SP 1-6, SP 1-7, NKA 1-5, and NKA 1-8 observed after treatment of the lungs with NEP inhibitors further supports this conclusion. When the effects of multiple inhibitors were studied, i.e., TCBLCB, the amount of the dipeptide His-Lys formed from ${ }^{125} \mathrm{I}$-Histidyl ${ }^{1} \mathrm{NKA}$ was decreased compared with thiorphan alone or SCH32615, although this effect did not result in a significant increase in total peptide recovery. It has been shown in a preparation of longitudinal muscle layer of guinea pig small intestine that NKA is a also a substrate for a bestatin sensitive aminopeptidase (36); inhibition of this aminopeptidase may account for the decreased recovery of this peptide.

In conclusion, our data demonstrate that NEP inhibition but not ACE inhibition significantly influences the effects of NKA and SP on airway smooth muscle when presented via the trachea. We also demonstrate that the cleavage of these tachykinins after airway infusion is consistent with the hypothesis that NEP, rather ACE, is the major enzyme controlling degradation of tachykinins that become available on the airway surface.

\section{Acknowledgments}

The authors thank Dr. Bernard Ransil for his helpful advice concerning statistical analysis.
This work was supported by grant HL-39827. Dr. Milton A. Martins is supported by the Brazilian National Council for Scientific Development (CNPQ).

\section{References}

1. Hua, X. Y., E. Theodorsson-Norheim, E. Brodin, J. M. Lundberg, and T. Hokpelt. 1985. Multiple tachykinins (neurokinin A, neuropeptide $k$ and substance $P$ ) in capsaicin-sensitive sensory neurons in the guinea-pig. Regul. Peptides. 13:1-19.

2. Lundberg, J. M., E. Brodin, and A. Saria. 1983. Effects and distribution of vagal capsaicin-sensitive substance $P$ neurons with special reference to the trachea and lungs. Acta Physiol. Scand. 119:243252.

3. Gashi, A. A., D. B. Borson, W. E. Finkbeiner, J. A. Nadel, and C. B. Basbaum. 1986. Neuropeptides degranulate serous cells of ferret tracheal glands. Am. J. Physiol. 251(Cell. Physiol. 20):C223-C229.

4. Borson, D. B., R. Corrales, S. Varsano, W. Gold, N. Viro, G. Caughey, J. Ramachandran, and J. A. Nadel. 1987. Enkephalinase inhibitors potentiate substance P-induced secretion of ${ }^{35} \mathrm{SO}_{4}$-macromolecules from ferret trachea. Exp. Lung Res. 12:21-36.

5. Al-Bazzaz, F. J., J. G. Kelsey, and W. D. Kaage. 1985. Substance P stimulation of chloride secretion by canine tracheal mucosa. Am. Rev. Respir. Dis. 131:86-89.

6. Lundberg, J. M., A. Saria, E. Brodin, S. Rosell, and K. Folkers. 1983. A substance $P$ antagonist inhibits vagally induced increase in vascular permeability and bronchial smooth muscle contraction in the guinea pig. Proc. Natl. Acad. Sci. USA. 80:1120-1124.

7. Sertl, K., C. J. Wiedermann, M. L. Kowalski, S. Hurtado, J. Plutchok, I. Linnoila, C. B. Pert, and M. A. Kaliner. 1988. Substance $P$ : The relationship between receptor distribution in rat lung and the capacity of substance $\mathrm{P}$ to stimulate vascular permeability. Am. Rev. Respir. Dis. 138:151-159.

8. Malo, P. E., M. A. Wasserman, T. J. Torphy, D. J. Parris, and D. F. Pfeiffer. 1986. Characterization of substance P-induced contractions of guinea pig trachea. J. Pharmacol. Exp. Ther. 237:782-786.

9. Gerard, N. P. 1987. Characterization of substance $P$ contractile activity on isolated guinea pig lung tissues. J. Pharmacol. Exp. Ther. 243:901-906.

10. Uchida, Y., A. Nomura, M. Ohtsuka, S. Hasegawa, K. Goto, S. Kimura, Y. Sugita, and Y. Uchiyama. 1987. Neurokinin A as a potent bronchoconstrictor. Am. Rev. Respir. Dis. 136:718-721.

11. Sekizawa, K., J. Tamaoki, J. A. Nadel, and D. B. Borson. 1987. Enkephalinase inhibitor potentiates substance P- and electrically induced contraction in ferret trachea. J. Appl. Physiol. 63:1401-1405.

12. Stimler-Gerard, N. P. 1987. Neutral endopeptidase-like enzyme controls the contractile activity of substance $P$ in guinea pig lung. J. Clin. Invest. 79:1819-1825.

13. Fine, J. M., T. Gordon, and D. Sheppard. 1989. Epithelium removal alters responsiveness of guinea pig trachea to substance $P$. $J$. Appl. Physiol. 66:232-237.

14. Thompson, J. E., and D. Sheppard. 1988. Phosphoramidon potentiates the increase in lung resistance mediated by tachykinins in guinea pigs. Am. Rev. Respir. Dis. 137:337-340.

15. Matsas, R., A. J. Kenny, and A. J. Turner. 1984. The metabolism of neuropeptides. The hydrolysis of peptides, including enkephalins, tachykinins and their analogues by endopeptidase-24.11. Biochem. J. 223:433-440.

16. Skidgel, R. A., S. Engelbrecht, A. R. Johnson, and E. G. Erdos. 1984. Hydrolysis of substance $P$ and neurotensin by converting enzyme and neutral endopeptidase. Peptides. 5:769-776.

17. Cascieri, M. A., H. G. Bull, R. A. Mumford, A. A. Patchett, N. A. Thornberry, and T. Liang. 1984. Carboxyl-terminal tripeptidyl hydrolysis of substance $P$ by purified rabbit lung angiotensin-converting enzyme and the potentiation of substance $P$ activity in vivo by captopril and MK-422. Mol. Pharmacol. 25:287-293.

18. Couture, R., and D. Regoli. 1981. Inactivation of substance $P$ and its C-terminal fragments in rat plasma and its inhibition by captopril. Can. J. Physiol. Pharmacol. 59:621-625. 
19. Yokosawa, H., S. Endo, Y. Ohgaki, J. Maeyama, and S. Ishii. 1985. Hydrolysis of substance $P$ and its analogs by angiotensin-converting enzyme from rat lung. Characterization of endopeptidase activity of the enzyme. J. Biochem. 98:1293-1299.

20. Hooper, N. M., A. J. Kenny, and A. J. Turner. 1985. The metabolism of neuropeptides. Neurokinin A (substance K) is a substrate for endopeptidase-24.11 but not for peptidyl dipeptidase A (angiotensin-converting enzyme). Biochem. J. 231:357-361.

21. Thiele, E. A., S. M. Strittmatter, and S. H. Snyder. 1985. Substance $K$ and substance $P$ as possible endogenous substrates of angiotensin converting enzyme in the brain. Biochem. Biophys. Res. Commun. 128:317-324.

22. Shore, S. A., N. P. Stimler-Gerard, S. R. Coats, and J. M. Drazen. 1988. Substance P-induced bronchoconstriction in the guinea pig. Enhancement by inhibitors of neutral metalloendopeptidase and angiotensin-converting enzyme. Am. Rev. Respir. Dis. 137:331-336.

23. Drazen, J. M., S. A. Shore, and N. P. Gerard. 1989. Substance P-induced effects in guinea pig lungs: effects of thiorphan and captopril. J. Appl. Physiol. 66:1364-1372.

24. Dusser, D. J., E. Umeno, P. D. Graf, T. Djokic, D. B. Borson, and J. A. Nadel. 1988. Airway neutral endopeptidase-like enzyme modulates tachykinin-induced bronchoconstriction in vivo. J. Appl. Physiol. 65:2585-2591.

25. Johnson A. R., J. Ashton, W. W. Schulz, and E. G. Erdos. 1985. Neutral metalloendopeptidase in human lung tissue and cultured cells. Am. Rev. Respir. Dis. 132:564-568.

26. Nucci, G., and S. Moncada. 1987. Release of vasoactive substances from guinea pig isolated lungs perfused via the trachea. Am. Rev. Respir. Dis. 135:S39-S41.

27. Folkesson, R., A. Neil, and L. Terenius. 1985. Enzyme-linked immunosorbent assay of substance $\mathrm{P}$ and its metabolite SP 1-7. A comparison with RIA. J. Neurosci. Methods. 14:169-176.

28. Roques, B. P., M. C. Fournie-Zaluski, E. Soroca, J. M. Le- comte, B. Malfroy, C. Llorens, and J. C. Schwartz. 1980. The enkephalinase inhibitor thiorphan shows antinociceptive activity in mice. $\mathrm{Na}$ ture (Lond.). 288:286-288.

29. Chipkin, R. E., J. G. Berger, W. Billard, L. C. Iorio, R. Chapman, and A. Barnett. 1988. Pharmacology of SCH 34826, an orally active enkephalinase inhibitor analgesic. J. Pharmacol. Exp. Ther. 245:829-838.

30. Burcher, E., S. H. Buck, W. Lovenberg, and T. L. O'Donohue. 1986. Characterization and autoradiographic localization of multiple tachykinin sites in gastrointestinal tract and bladder. J. Pharmacol. Exp. Ther. 236:819-831.

31. Cascieri, M. A., G. G. Chicci, and T. Liang. 1985. Demonstration of two distinct tachykinin receptors in rat brain cortex. J. Biol. Chem. 260:1501-1507.

32. Schults, C. W., R. Quirion, B. Chronwall, T. N. Chase, and T. L. O'Donohue. 1984. A comparison of the anatomical distribution of substance $P$ and substance $P$ receptors in the rat central nervous system. Peptides. 5:1097-1128.

33. Schwartz, J. C., B. Malfrey, and S. Baume. 1981. Biological inactivation of enkephalins and the role of enkephalin-dipeptidyl-carboxypeptidase ("enkephalinase") as neuropeptidase. Life Sci. 29:1715-1740.

34. Hudgin, R. L., S. E. Charleson, M. Zimmerman, R. Mumford, and P. L. Wood. 1981. Enkephalinase: selective peptide inhibitors. Life Sci. 29:2593-2601.

35. Matsas, R., I. S. Fulcher, A. J. Kenny, and A. J. Turner. 1983. Substance $P$ and [Leu]enkephalin are hydrolized by an enzyme in pig caudate synaptic membranes that is identical with the endopeptidase of kidney microvilli. Proc. Natl. Acad. Sci. USA. 80:3111-3115.

36. Nau, R., G. Schafer, C. F. Deacon, T. Cole, D. V. Agoston, and J. M. Conlon. 1986. Proteolytic inactivation of substance $P$ and neurokinin A in the longitudinal muscle layer of guinea pig small intestine. J. Neurochem. 47:856-864. 